\title{
Translocation of a single coronary artery from the nonfacing sinus in the arterial switch operation: Long-term patency of the interposition graft
}

\author{
Igor E. Konstantinov, MD, PhD, ${ }^{\text {a }}$ Tyson A. Fricke, BMedSci, ${ }^{a}$ Yves d'Udekem, MD, PhD, ${ }^{\text {a }}$ and \\ Dorothy J. Radford, MBBS, MD, ${ }^{\mathrm{b}}$ Melbourne and Brisbane, Australia
}

In the current era, a single coronary artery originating from one of the facing sinuses is no longer a risk factor for the arterial switch operation (ASO) in high-volume units. ${ }^{1,2} \mathrm{Al}-$ though an anterior looping or a commissural malalignment increases the distance between the original coronary orifice and neoaorta, ${ }^{1,3,4}$ both anatomic variations can still be managed successfully by means of tube reconstruction of the single coronary artery with autologous pericardium or aorta. ${ }^{3,4}$ However, a single coronary artery originating from a nonfacing sinus presents a rare yet significant problem, often making ASO impossible. Herein we describe a successful translocation of the single coronary artery with an interposition graft, with a documented patency at 20 years of follow-up.

\section{CLINICAL SUMMARY}

Between May 1983 and January 2009, 720 ASOs were performed at the Royal Children's Hospital in Melbourne.

From the Department of Cardiac Surgery, ${ }^{\text {a }}$ Royal Children's Hospital, Melbourne, and the Adult Congenital Heart Unit, ${ }^{\mathrm{b}}$ the Prince Charles Hospital, Brisbane, Australia. Disclosures: None.

Received for publication March 1, 2010; revisions received March 27, 2010; accepted for publication June 2, 2010; available ahead of print July 5, 2010.

Address for reprints: Igor E. Konstantinov, MD, PhD, Royal Children's Hospital, Flemington Rd, Parkville, Victoria 6009, Australia (E-mail: igor.konstantinov@ rch.org.au).

J Thorac Cardiovasc Surg 2010;140:1193-4 0022-5223/\$36.00

Crown Copyright (C) 2010 Published by Elsevier Inc. on behalf of The American Association for Thoracic Surgery

doi:10.1016/j.jtcvs.2010.06.002
Twenty-one $(2.9 \%)$ of 720 had double ASOs for congenitally corrected transposition of the great arteries. Two $(9.5 \%)$ of 21 had a single coronary artery arising from the nonfacing sinus of Valsalva. Both had ventricular septal defects and Ebstein's anomaly of the morphologically tricuspid (systemic) valve.

One neonate died after an unsuccessful attempt to translocate the single coronary artery during double ASO and concomitant coarctation of aorta repair. Another patient had pulmonary artery (PA) banding at 2 months of age. $\mathrm{He}$ was planned for a double-switch procedure at 3 years of age. However, during the operation, the ASO was deemed impossible because of the long distance from the PA to the coronary artery (Figure 1, A). Instead, he underwent PA debanding, systemic tricuspid valve replacement with a 27-mm St Jude mechanical prosthesis (St Jude Medical, Minneapolis, Minn), ventricular septal defect closure, and placement of an epicardial pacemaker. He had rapidly progressive heart failure with a systemic ventricular ejection fraction of $10 \%$ and multiple episodes of pulmonary edema and was listed for transplantation within 3 months of surgical intervention. On July 5, 1989, the patient underwent a Senning procedure and ASO with single coronary artery translocation using 6-mm bovine carotid artery (Artegraft, North Brunswick, NJ) and PA repair with autologous pericardium (Figure 1, B). The Lecompte maneuver was not possible because the main PA could not reach the proximal aorta. Thus the neo-PA was left behind the neoaorta.
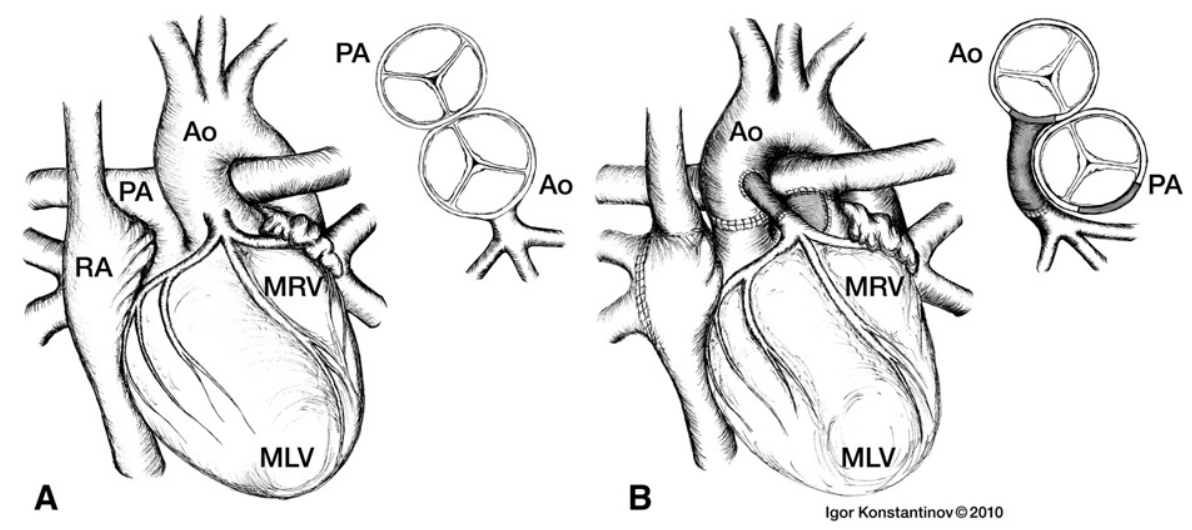

FIGURE 1. Schematic of anatomy of the single coronary artery before (A) and after (B) the double-switch operation and translocation of the coronary artery with interposition graft. $A o$, Aorta; $M L V$, morphologic left ventricle; $M R V$, morphologic right ventricle; $P A$, pulmonary artery; $R A$, right atrium. 

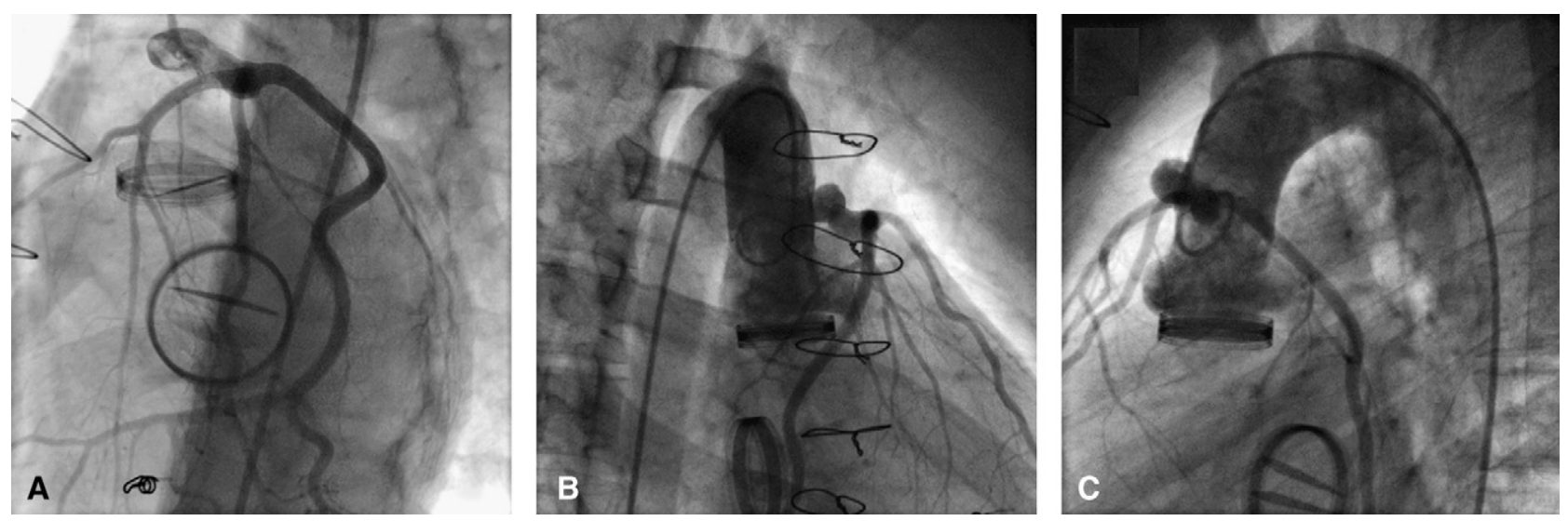

FIGURE 2. Coronary angiogram showing patent interposition graft and coronary arteries (A) and their relationships to the ascending aorta and mechanical prostheses (B and C).

The patient subsequently underwent replacement of the prosthesis with a 29-mm ATS device (ATS Medical, Inc, Minneapolis, Minn) in 1997, aortic valve replacement with a 25-mm ATS device in 2006, and epicardial pacemaker change in 2001 and 2006. In November 2009, he was admitted with shortness of breath (SOB). Echocardiographic analysis demonstrated a systemic ventricular ejection fraction of $35 \%$. Because patients after ASO might not have classic angina pectoris symptoms and pacing makes detection of myocardial ischemia by means of electrocardiographic analysis impossible, the SOB can be the only symptom of myocardial ischemia. Coronary angiography was performed on November 5, 2009, and demonstrated a patent interposition graft and coronary arteries (Figure 2). The patient has been anticoagulated with a combination of aspirin and warfarin since graft implantation. The cause of his SOB was likely a fluid overload as the patient's symptoms improved significantly with diuretics and afterload reduction therapy, and he continues to do well.

\section{DISCUSSION}

A single coronary artery originating from the noncoronary sinus is rare, yet it presents a challenge during ASO. Tension-free anastomosis of the coronary artery to the neoaorta is often impossible without an interposition graft. Thus these patients might be regarded as "unswitchable" because of the coronary anomaly. Failure of the morphological right (systemic) ventricle would leave transplantation or a mechanical assist device as the only option.

This report demonstrates that a successful double-switch operation can be achieved in a patient with a single coronary artery originating from the nonfacing sinus with an excellent long-term result. A long-term patency of the coronary arteries can be achieved with a bovine carotid artery interposition graft. The graft remained patent and free of calcifications during a 20-year period despite 2 subsequent intracardiac procedures. The bovine carotid artery conduit was first described in 1966 and has been used extensively in vascular surgery as an arteriovenous graft for hemodialysis through the 1970s and 1980s before it was replaced with expanded polytetrafluoroethylene grafts. ${ }^{5}$ Recently, an interest in the bovine carotid artery graft has been renewed. ${ }^{5}$ The graft is presently available in 6-, 7-, and 8-mm diameters with lengths of 15 to $45 \mathrm{~cm}$ (Artegraft; Artegraft, Inc, North Brunswick, NJ). The graft might be a valuable alternative in rare patients with a single coronary artery undergoing ASO, particularly when autologous tissues are not available.

The original operation was performed in 1989 by Dr Roger Mee.

\section{References}

1. Scheule AM, Zurakowski D, Blume ED, Stamm C, del Nido PJ, Mayer JE, et al. Arterial switch operation with s single coronary artery. J Thorac Cardiovasc Surg. 2002;123:1164-72.

2. Qamar ZA, Goldberg CS, Devaney EJ, Bove EL, Ohye RG. Current risk factors and outcome for the arterial switch operation. Ann Thorac Surg. 2007;84:871-9.

3. Kim SJ, Kim WH, Lim C, Oh SS, Kim YM. Commissural malalignment of aorticpulmonary sinus in complete transposition of great arteries. Ann Thorac Surg. 2003;76:1906-10.

4. Mace L, Vanhuyse F, Jellimann JM, Youssef D, Moulin-Zinsch A, Lethor JP, et al. Arterial switch operation with a single coronary artery: the autograft concept. AnnThorac Surg. 2009;87:1967-8.

5. Anderson C, Richardson CJ, Ney Al, et al. Renewed interest in bovine heterograft for vascular access for vascular access; a comparison between polytetrafluoroethylene and bovine. In: Henry ML, ed. Vascular access for hemodialysis IX. Los Angeles: Bonus Books; 2005. p. 185-93. 